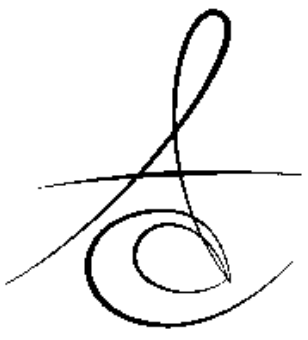

\title{
ÇİFT TARAFLI YÜKLEME ALTINDA FARKLI MUKOZA KALINLIKLARININ İKİ TİP İMPLANT DESTEKLİ OVERDENTURE DİZAYNI ÜZERİNDEKİ STRES DAĞILIMINA ETKİSİ: FOTOELASTİK STRES ANALİZi
}

\author{
EFFECT OF DIFFERENT MUCOSA THICKNESS ON STRESS DISTRUBITION \\ OF TWO DIFFERENT IMPLANT-SUPPORTED OVERDENTURE DESIGNS \\ UNDER BILATERALLY LOADING: PHOTOELASTIC STRESS ANALYSIS
}

\author{
Dr Öğretim Üyesi Özgün Yusuf ÖzYILMAZ*
}

Prof. Dr. Filiz AYKENT**

Makale Kodu/Article code: 3583

Makale Gönderilme tarihi: 17.04 .2018

Kabul Tarihi: 19.09 .2018

\section{öz}

Amaç: Bu çalışmanın amacı fotoelastik stres analiz yöntemi kullanılarak çift taraflı yükleme altında farklı mukoza kalınlığının, iki implant destekli mandibular overdenture tasarımları üzerindeki stres dağılımına etkisini değerlendirmektir.

Gereç ve Yöntem: Kaninler bölgesine iki adet bağımsız implant (4,0x11 mm; Fixture Osseospeed İmplant, Astra Tech, Mölndal, İsveç) yerleştirilerek altı adet alt çene dişsiz fotoelastik modeller üretildi. Çalışılan ataçman sistemler, locator ve ball stud ataçman sistemlerdi. Ball ve locator grupların her ikisi de, farklı mukoza kalınlıkları (1mm-1mm, $1 \mathrm{~mm}-2 \mathrm{~mm}, 1 \mathrm{~mm}-4 \mathrm{~mm}$ ) sağlayan farklı rezidüel kret yüksekliğine sahip üç farklı modelden oluşmaktadır. Birinci molarların santral fossalarına çift taraflı olarak $135 \mathrm{~N}$ statik vertikal kuvvet uygulandı. Modeller, yükleme altında implantların etrafında ve implantlar arası bölgede izokromatik fringeleri gözlemek için dairesel polariskop alanına yerleştirildi. Fotoelastik stres fringeleri monitörize edildi ve fotoğrafik olarak kaydedildi.

Bulgular: Ball ataçman grupların tüm test modellerinde locator gruplardan daha yüksek stres değerleri gözlendi. Her iki ataçman tasarımında en düşük stres değerleri $1 \mathrm{~mm}-1 \mathrm{~mm}$ mukoza kalınlığındaki modellerde görüldü. Locator grupların ball ataçman gruplara göre stresi daha homojen dağıttığı gözlendi.

Sonuç: Bu çalışmanın sonucuna göre, protez yapımı için yerleştirilen implantlar arasında farklı mukoza kalınlıkları varlı̆ında locator ataçman seçimi ball ataçmana göre daha dengeli stres dağılımı sebebiyle avantaj sağlamaktadır.

Anahtar Sözcükler: Fotoelastik stres analiz; mukoza kalınlık; stres dağıııı; çift taraflı yükleme

\section{ABSTRACT}

Aim: The aim of this study was to evaluate the effect of different mucosa thickness on the stress distrubition of two implant-retained mandibular overdenture designs under bilaterally loading using photoelastic stress analysis method.

Material and Methods: Six photoelastic models of an edentulous mandibular were fabricated with solitary two implants $(4,0 \times 11 \mathrm{~mm})$ which were placed in the canine regions. The attachment systems studied were ball and locator stud attachments. Both ball and locator attachment groups that mucosa assumed three characteristics of thickness (1mm-1mm, 1mm-2mm, $1 \mathrm{~mm}-4 \mathrm{~mm})$. Static vertical force of $135 \mathrm{~N}$ was applied bilaterally to the central fossa of the first molars. Models were positioned in the field of circular polariscope to observe the distribution of isochromatic fringes around the implants and interimplant areas under loading. The stress fringes were monitored and recorded photographically.

Results: Higher stress values were observed ball attachment groups than locator groups in all test models. Lowest stress values were seen in stimulated $1 \mathrm{~mm}-1 \mathrm{~mm}$ mucosa thickness model for both attachment designs. It was observed that locator groups distributed stress more homogenous than ball attachment groups.

Conclusion: According to the result of this study, choice of locator attachment in the presence of different mucosal thicknesses among the implants placed for prosthetic treatment provides more advantage than ball attachment due to more balanced stress distribution.

Key words: Photoelastic stress analysis; mucosa thickness; stress distribution; bilateral loading

\footnotetext{
* İstanbul Bezmialem Vakıf Üniversitesi, Diş Hekimliği Fakültesi, Protetik Diş Tedavisi AD, İstanbul.

** Yıldııım Beyazıt Üniversitesi, Diş Hekimliği Fakültesi, Protetik Diş Tedavisi AD, Ankara.

₹ 101th Annual World Dental Congress (FDI), Istanbul, Turkey, 28-31 August 2013

${ }^{\ddagger}$ Bu araştırma Selçuk Üniversitesi Bilimsel Araştırma Projeleri Koordinatörlüğg̈ü

tarafindan 10202052 proje numarası ile desteklenmiştir.
}

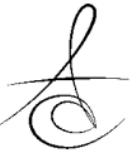




\section{GİRİş}

Dişsiz hastaların kullandıkları diş protezi ile ilgili şikayetlerinin temel nedeni protezlerindeki fonksiyonel retansiyon ve stabilizasyon eksikliğidir. ${ }^{1}$ Aynı zamanda bu hastaların alt çenelerindeki kemik rezorpsiyonu üst çenelerinden anlamlı derecede daha fazla gözlenmektedir. Maruz kaldıkları alt çenedeki bu doğal süreçten dolayı bu hastaların implant rehabilitasyonu ile protezlerinin tutuculuğunun ve desteğinin arttırılmasına ihtiyaç vardır. ${ }^{2}$ Birçok çalışmada ${ }^{3-7}$ implant rehabilitasyonu için yüksek başarı oranı bildirildiği için, aşırı rezorbe krete sahip olan hastalarda overdenture protezler kabul edilebilir bir alternatif haline gelmektedir. İmplant destekli overdenture protezler, özellikle alt çenede tamamen dişsiz hastalarda ilk tedavi yaklaşımı olarak kullanılmaktadır. ${ }^{2} \mathrm{Bu}$ protezler konvansiyonel tam protezlere göre, daha fazla retansiyon, stabilite, artmış konfor ve çiğneme aktivitesi, ${ }^{1,8}$ rezidüel sırtın korunması, geliştirilmiş yaşam kalitesi gibi bazı avantajlar göstermektedir. ${ }^{8}$

McGill Consensus 2002 bildirisine göre, tamamen dişsiz hastalarda iki bağımsız implant kullanılarak implant destekli alt çene overdenture protezi yapımı ilk tedavi seçeneği olarak kabul edildi. ${ }^{2,4}$ İki implantın desteklediği overdenture protezler, dokuda oluşturduğu düşük cerrahi hasar, düşük maliyet ve yüksek tutuculuk ile en temel tedavi gereksinimlerini karşılayarak en uygun protez prosedürü olarak sayılmaktadır. ${ }^{10}$ İki implant destekli alt çene overdenture protezler için yaygın olarak kullanılan abutment tipleri farklı tasarımları ile beraber bar, ball ve mıknatıs ataçmanlardır. ${ }^{11-14}$ Son yıllarda popüler olarak yaygın kullanıma sunulan ve implant şirketleri tarafından pazarlanan locator sistemi olarak adlandırılan alternatif tekli bağlantıya sahip olan yeni ataçman sistemi literatürde en çok kullanılan ball ataçman sistemine karşı piyasaya sürülmektedir. Her iki implant bağlama sistemi de implant endüstrisinde kullanılmasına rağmen, farklı implant yüksekliklerinde ve mukoza kalınlığında stres dağılımları hakkında birbirleri ile ilgili detaylı bilgi ve farklı görüş ayrılıkları mevcut değildir. ${ }^{15-17}$

İmplant ataçmanlarının konumlandırıması iki implantlı overdenturelar için çok önemlidir, çünkü implantların çevresindeki kemikte patolojik aşırı yüklenme durumunda aşırı stres ve gerinim gradyanlarından dolayı rezorbsiyon ve deformasyon meydana gelir. $\mathrm{Bu}$ durum ayrıca implant sisteminin bileşenlerinin uyumsuzluğuna ve implantta mikro kırığa yol açabilir. Bu görevleri gerçekleştirmek ve böylece implant destekli protezlerin başarı oranlarını arttırmak için implantlar ataçmanların birbirleriyle yükseklik farkları açısından en uygun konuma yerleştirilmelidir. ${ }^{11,18}$ Klinisyenler, iki birbirinden bağımsız implantın, okluzal düzleme paralel olarak aynı oklüzal yükseklikte konumlandırılmasını sağlamalıdır. Eğer bir implant diğerinden daha yüksekse, fonksiyon esnasında protez daha kısa olan implanttan ayrılır ve öncelikle daha yüksek olan implant üzerinde döner. Bu durum, daha düşük seviyede olan implant üzerindeki ataçmanın aşınmasını hızlandıracaktır ve daha yüksekte olan implantta ise okluzal yükün çoğunluğunu aldığı için, artan miktarda krette kemik kaybı meydana gelecektir. ${ }^{18,19}$

Ataçman yüksekliği ve mukoza kalınlığı, implant destekli overdentureler'ın tasarımında önemli faktörlerdendir. Peri-implant kemiğine iletilen stres seviyesini artıran kaldıraç kolu etkisini azaltmak için, ataçman yüksekliği mümkün olduğunca kısa olmalıdır. Ataçmanın yüksekliği ayrıca protezin içindeki alan gereksinimlerini de etkiler ve yetersiz akrilik reçine kalınlığından dolayı çatlaklar oluşabilir. Bu sebeplerden dolayı ataçman yüksekliklerinin ve buna bağlı mukoza kalınlıklarının en uygun pozisyonda olması protezin prognozunu olumlu yönde etkiler. ${ }^{20,21}$

Dental implant sistemi etrafındaki stresin değerlendirilmesi için fotoelastik analiz, sonlu elemanlar analizi ve kemik yüzeyinde gerinim ölçümleri gibi çeşitli yöntemler kullanılmaktadır. Bu yöntemlerin içinde; fotoelastik analiz, hem hasta hem de uygulayıc değişkenlerini kısıtlayan deneysel bir tasarıma izin verir. Bu teknik, diş hekimliğinde protez restorasyonların ve implantların fiziksel özellikleri ve doku yanıtı etkileşimini incelemek için yaygın olarak kullanılmaktadır. ${ }^{22}$ Sonlu elemanlar analizi ${ }^{8,18}$ ve gerinim ölçümleri $^{23}$ kullanılarak aynı kemik yüksekliğinde aynı boyutta ataçmanlar kullanılarak implantlar çevresinde stres dağılımını değerlendirmek için çeşitli çalışmalar yapılmaktadır ancak farklı kemik yüksekliğine bağlı farklı yükseklikteki ataçman ve mukoza yüksekliklerini değerlendiren ve fotoelastik analizi kullanan hiçbir çalışma yoktur. Bu çalışmada implant üstü overdenture protezlerde implantlar çevresinde farklı mukoza kalınlıkları varlığında farklı overdenture dizaynlarının (locator ve ball ataçman) iki taraflı okluzal yükler altındaki implant-kemik arayüzeyinde oluşan stres konsantrasyonlarının fotoelastik stres analizi yöntemi 
ile incelenmesi amaçlanmıştır. Çalışmamızın ispat edilmemiş hipotezi implantlar etrafında farklı mukoza kalınlıkları olduğunda locator ve ball ataçman dizaynlarının implantlarda oluşan stres açısından bir fark oluşturmayacağıdır.

\section{GEREÇ VE YÖNTEM}

Alt çene deney modellerini oluşturmak için 4,0 $\mathrm{mm}$ çapında, $11 \mathrm{~mm}$ uzunluğunda 12 adet dental implant (Fixture Osseospeed İmplant, Astra Tech, Mölndal, Sweden) kullanıldı. İki bağımsız implantla desteklenen alt çene overdenture protez yapımında en az $10 \mathrm{~mm}$ uzunluğunda implantların kullanımı önerilmektedir. ${ }^{24,25}$ İki farklı ( ball ataçman ve locator) tutucu tipi kullanılan çalışmada farklı dişeti yüksekliklerinde 6 çalışma modeli oluşturuldu (Tablo 1).

Tablo 1. Çalışma grupları

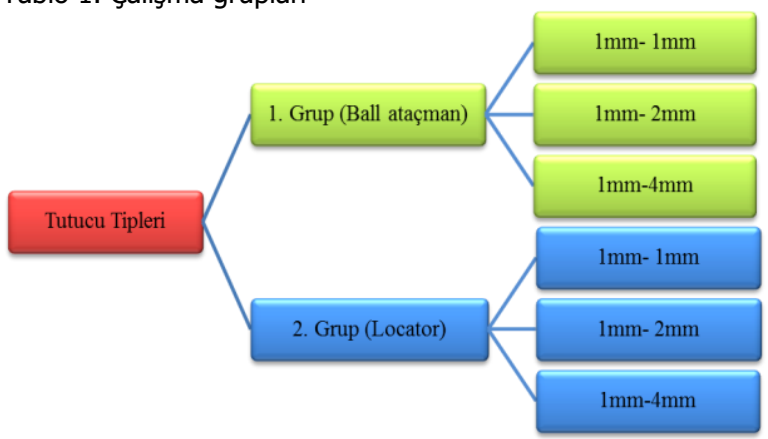

Mum ve Akrilik Modellerin Hazırlanması

İmplantların yerleştirilebilmesi için yeterli kemik yüksekliğine sahip alt çene total dişsiz hastadan bir elastomerik ölçü maddesiyle (Zetaplus, Zhermack, Rovigo, İtalya) ölçü alınarak önce alçı model daha sonra mum model elde edildi. Mum modelin alt tabanı ilave ile yükseltilerek tüm model oluşturuldu. Tüm modelden elastomerik ölçü maddesiyle negatifi elde edilip ikinci bir mum model oluşturuldu. Bu ikinci mum modelin orta hattı belirlenip dijital kumpas yardımıyla sol alt çene bölgesi sağ bölgeye göre $1 \mathrm{~mm}$ aşağıda olacak şekilde (kemik seviyeleri sağ bölgeden- sol bölgeye; $1 \mathrm{~mm}-2 \mathrm{~mm}$ ) şekillendirildi. Bu şekillendirilen modelden ölçü alınarak elde edilen üçüncü modelde sol taraf $3 \mathrm{~mm}$ daha da aşağıda olacak şekilde (kemik seviyeleri sağ bölgeden-sol bölgeye; 1mm-4mm) olarak şekillendirildi. Sonuçta ilk mum modelden basamak basamak şekillendirilerek oluşan farklı kemik seviyelerine sahip 3 mum model elde edilmiş oldu. Bu modellerin ölçüleri alınıp duplike edilerek toplamda 6 mum model elde edildi. Mum modeller akril tepimi için muflaya alınıp ISı ile polimerize olan akrilik rezin (Meliodent; Heraeus Kulzer, Hanau, Almanya) tepilerek 6 adet akrilik model hazırlandı. Akrilik modeller sırasıyla 320-, 400-, 600- grid' lik silikon karbit zımpara kağıdı ile zımparalanarak parlatma işlemine tabi tutuldu.

Akrilik Modellere İmplantların Yerleştirilmesi Modellere ilgili literatürler de belirtildiği gibi kanin dişler arasındaki $22 \mathrm{~mm}$ 'lik mesafe olacak şekilde ikişer implant yuvası açıldı. ${ }^{22,26,27}$ Her iki implant orta hattan 11 'er mm uzakta olacak şekilde dijital kumpas yardımıyla noktalar belirlenip işaretlendi. Akrilik modellere implantların birbirine paralel olarak yerleştirilebilmesi için bir paralelometre (Orthofex, Fogászat Gyártơ, KFT, Budapest, Hungary) kullanıldı. Yumuşak doku seviyesindeki implantlar hazırlanan yuvalarına parlak yüzeyleri kret seviyesinde kalacak şekilde raşet yardımıyla yerleştirildi.

Yerleştirilen implantların $1 \mathrm{~mm}-1 \mathrm{~mm}, 1 \mathrm{~mm}-$ $2 \mathrm{~mm}, 1 \mathrm{~mm}-4 \mathrm{~mm}$ dişeti yüksekliklerini sağladıklarından emin olmak için ball ve locator ataçmanların titanyum tutucu parçaları önceden modellere yerleştirilen implantlarla birleştirildi. Ball ataçman tutucular için topuz kısmın en tepesi; locator ataçman için ise bukkal en tepe noktası referans alınarak paralelometreye takılan frez temas ettirilip cihaz o aksta sabitlendi. Cihazın sabitliği bozulmadan yay hareketi yaptırılarak karşıt taraftaki topuz tepesine değip değmediği kontrol edildi. Bu işlem sırasında her iki taraftada aynı aksta temas olduğundan emin olunsa da topuz tepelerinin aynı düzlemsel doğrudan geçip geçmediğine, vertikal yüksekliklerinin aynı olup olmadığına paralelometrenin yan tarafında bulunan aşağı-yukarı hareketinin mm'lik değişimini gösteren çizgileri kontrol edilerek kesin ayarlamalar yapıldı (Resim 1).

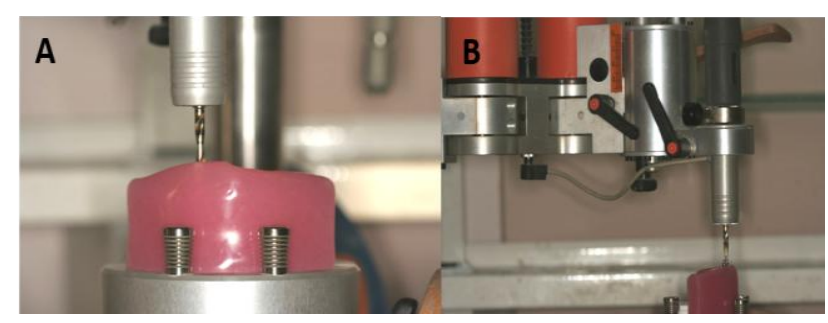

Resim 1. A.Paralelometre ile yuva açılması B. Kemik yüksekliklerinden emin olmak için mm'lik ölçümler

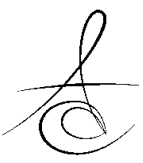




\section{Fotoelastik Modellerin Hazırlanması}

Akrilik modellerdeki tutucu parçalar çıkartılıp yerlerine implant transfer parçaları yerleştirilip elastomerik ölçü maddesiyle negatif elde edildi. Akrilik modellere yerleştirilen implantlar ve onlara bağlı transfer parçaları çıkartıı negatif boşluklara dikkatlice yerleştirildi. Fotoelastik rezin (PL-2 ve PLH-2, Measurements Group Inc., North Carolina, USA) üretici firmanın talimatları doğrultusunda karıştırılarak kalıba döküldü. Hazırlanan epoksi rezin örnekler etüv oda ISIsına gelinceye kadar bekletildikten sonra, polimerizasyonun tamamlanması için, 24 saat daha bekletildi. Fotoelastik modellerin tesfiye ve polisajları yapıldı.

\section{Mukoza Morfolojisinin Oluşturulması}

Model üzerinde protez bitim işlemleri stres oluşturabileceğinden bu işlemler için alçı modeller oluşturuldu. İmplantların orta hatta uzaklığı kadar olan mesafe implantların distal bölgelerinde aynı uzaklık olarak bırakılıp sabit kalem yardımıyla işaretlendi. Orta hattın merkezde implant olacak şekilde distal bölgedeki izdüşümü bir sabit kalemle işaretlendi. Orta hat ile iz düşümü arasındaki toplam uzaklık implant çevresi olarak tanımlandı. Böylece implantların hem mezial bölgeden orta hatta hem distal bölgeden izdüşüm noktalarına simetrik uzaklıkta olmaları sağlandı. İzdüşüm noktalarından sonraki serbest sonlanan posterior bölgeler $3 \mathrm{~mm}$ kalınlığında ${ }^{27,28}$ ışık ile polimerize olan baz plak (Vertex U.V Light Curing Trayplast, Vertex Dental, Zeist, Hollanda) hazırlanarak modele sabitlendi. Anterior bölgedeki mukoza ise her modele göre farklı yüksekliklerde oluşturuldu (Resim 2).

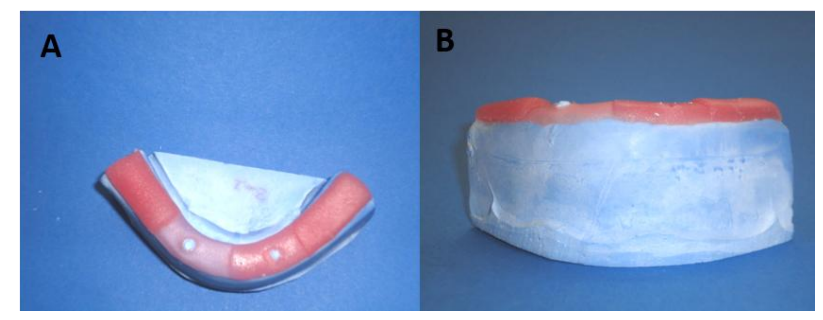

Resim 2. Mukoza şekillendirilmesi A. Okluzal görünüm B. Frontal görünüm

\section{Diş Diziminin Standardizasyonu ve Protezlerin Bitim İşlemleri}

Mukoza yüksekliği baz plakla ayarlanmış modelin üzerine plaka pembe modelaj mumu yerleştirilerek diş dizimi yapıldı. Bu modelden elastomerik ölçü maddesi ile ölçüsü alınarak toplamda içinde diş dizimi negatifi olan 6 kalıp elde edildi. Böylece tüm modellerde diş dizimi standardize edildi. Mum atımından sonra negatifinin içerisinde kalan dişlerin bulunduğu kalıba ISı ile polimerize olan şeffaf akril (Orthoplast, Vertex Dental, Zeist, Hollanda) döküldü. Mukoza oluşturulmuş alçı model kalıba yerleştirildi ve biodent fırını (Dikan 105, Mersin, Türkiye) içinde $55^{\circ} \mathrm{C}$ sıcaklıkta 2,5 bar altında 10 dakika bekletildi. Protez yapımında şeffaf malzemenin kullanımasıyla, stres çizgilerini gözlemlemek için ışığın, modelin tamamından geçmesi amaçlandı. ${ }^{22,27}$ Işık ile polimerize baz plak kullanıımasındaki amaç ise; şeffaf akrilin Isı ile polimerizasyonu esnasında onunla kimyasal tepkimeye girip şeffaf akrille birleşmesini engellemek ve yapılan $\mathrm{mm}^{\prime}$ lik mukoza ölçümlerinin bu birleşmeye bağlı olarak bozulmaması sağlamaktır. Modeller üzerine ball ataçman ve locator abutmentlar yerleştirilerek process kitleri ve titanyum dişi parçalarıyla ${ }^{28}$ overdenture protezleri implantlara birleştirme işlemi yapıldı. Fotoelastik modelde mukozayı taklit etmek için protez iç yüzeyinde ışık ile polimerize olan baz plakla oluşturulan boşluğa akışkan kivamlı elastik materyal (Gingifast; Zhermack SpA, Badia Polesine, İtalya) konularak fotoelastik modele uyumlandı, taşan parçalar temizlendi. Protez kaideleri fotoelastik modellerin fotoğraflanması esnasında implantların çevresindeki stres çizgilerini rahatça görebilmek için şekillendirildi (Resim 3).

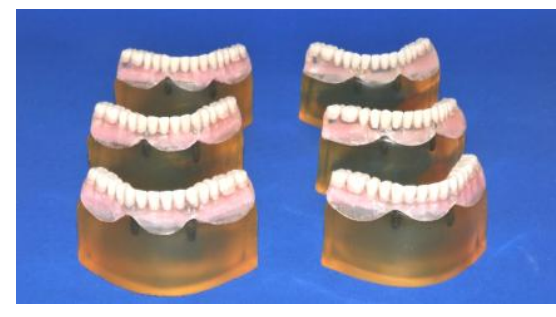

Resim 3. Modellere yerleştirilmiş protezler

\section{Modellerin Polariskop Cihazında Yüklenmesi}

Yükleme işlemi üniversal test cihazında gerçekleştirildi (TSTM 02500, Elista Ltd. Şti., İstanbul, Türkiye). Fotoğrafların alınma esnasında net görüntü elde etmek için makro objektifi (Macro Lens-Canon EF $100 \mathrm{~mm} \mathrm{F/2,8,} \mathrm{Canon} \mathrm{Inc.} \mathrm{Headquarters,} \mathrm{Tokyo,}$ Japan) bulunan bir dijital fotoğraf makinası (Canon EOS 650D, Canon Inc. Headquarters, Tokyo, Japan) kullanıldı. Modeller yükleme esnasında daha net

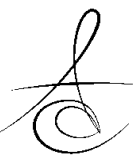


görüntü alabilmek için cihaza yerleştirilmeden önce bir pamuk yardımıyla makine yağı (Castrol, İstanbul, Türkiye) sürülerek parlatıldı. Modellere 13,7 kg (135 N) yük, birinci molarların santral fossasından aynı anda olmak üzere çift taraflı olarak vertikal kuvvetleri taklit etmek amacıyla dikey yönde uygulandı. ${ }^{28,30}$ Birinci molar dişin yükleme işlemi için seçilmesinin nedeni; maksimum okluzal kuvvetler çoğu kez bu bölgede oluşur ki bu bölge elevator kaslarının maksimum kasıldığı etki alanıdır. ${ }^{22,26}$ Her yüklemeden sonra fotoelastik modeller içerisinde hapsolan stres çizgilerinin elimine edilmesi için modeller $50^{\circ} \mathrm{C}^{\prime}$ de 20 dakika etüv'de bekletidi. ${ }^{28}$ Her yüklemeden önce modeller polariskop cihazında incelenerek stres birikim çizgileri olmadığından emin olundu.

\section{BULGULAR}

Fotoelastik modellerde stres seviyelerinin değerlendirilmesinde, beyaz ışık altında polariskop içinde oluşan renklerin fringe sırasını rakamsal olarak ifade etmek için ASTM D4093-95' in (Amerikan Test ve Materyal Topluluğu) tavsiye ettiği tablo kullanıldı. ${ }^{31}$ (Tablo 2) Stres değerleri ve fringeleri Tablo 3 ve Resim 4' de gösterilmiştir.

Tablo 2. ASTM' ye göre izokromatik fringe sıraları

\begin{tabular}{|c|c|c|}
\hline Renkler & $\begin{array}{l}\text { Fringe } \\
\text { SIrası (N) }\end{array}$ & \multirow{7}{*}{$\begin{array}{l}\text { Düşük } \\
\text { Seviye }\end{array}$} \\
\hline Siyah & 0 & \\
\hline Gri & 0,28 & \\
\hline Beyaz & 0,45 & \\
\hline Açık Sarı & 0,60 & \\
\hline Turuncu & 0,80 & \\
\hline Donuk Kırmızı & 0,90 & \\
\hline Mor (1. Bölüm geçişi) & 1,00 & \multirow{10}{*}{$\begin{array}{l}\text { Orta } \\
\text { Seviye }\end{array}$} \\
\hline Koyu Mavi & 1,08 & \\
\hline Mavi-Yeşil & 1,22 & \\
\hline Yeşil-Sarı & 1,39 & \\
\hline Turuncu & 1,63 & \\
\hline Pembemsi Kırmızı & 1,82 & \\
\hline Mor (2. Bölüm geçişi) & 2,00 & \\
\hline Yeșil & 2,35 & \\
\hline Yeşil-Sarı & 2,50 & \\
\hline Kırmızı & 2,65 & \\
\hline Kırmızı-Yeşil (3.Bölüm geçişi) & 3,00 & \multirow{5}{*}{$\begin{array}{l}\text { Yüksek } \\
\text { Seviye }\end{array}$} \\
\hline Yeşil & 3,10 & \\
\hline Pembe & 3,65 & \\
\hline Pembe-Yeșil geçiş & 4,00 & \\
\hline Yeșil & 4,15 & \\
\hline
\end{tabular}

\begin{tabular}{|c|c|c|c|c|c|c|c|}
\hline $\begin{array}{c}\text { Ataçman } \\
\text { Tipi }\end{array}$ & $\begin{array}{c}\text { Yükleme } \\
\text { Sahası }\end{array}$ & \multicolumn{2}{|c|}{$1-1$} & \multicolumn{2}{c|}{$1-2$} & \multicolumn{2}{c|}{$1-4$} \\
\hline Ball & Çift & 1,82 & 1,63 & 2,00 & 1,63 & 2,50 & 2,35 \\
\hline Locator & Çift & 1,63 & 1,39 & 2,35 & 1,63 & 1,39 & 1,63 \\
\hline
\end{tabular}

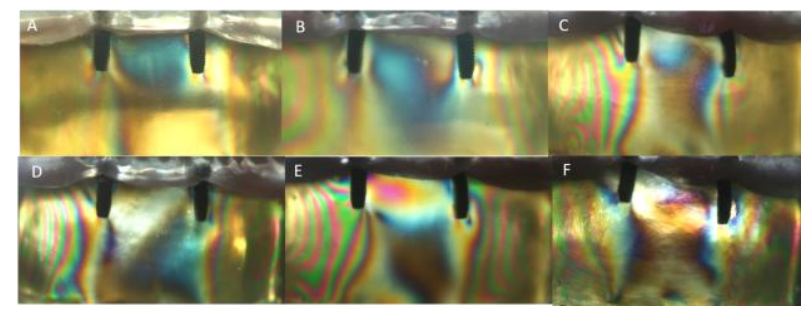

Resim 4. Stres bantları A. 1mm-1mm ball ataşman model B. $1 \mathrm{~mm}-2 \mathrm{~mm}$ ball ataşman model C. $1 \mathrm{~mm}-4 \mathrm{~mm}$ ball ataşman model D. $1 \mathrm{~mm}-1 \mathrm{~mm}$ locator ataşman model E. $1 \mathrm{~mm}-2 \mathrm{~mm}$ locator ataşman model F. $1 \mathrm{~mm}-4 \mathrm{~mm}$ locator ataşman model

\section{Çift taraflı yükleme yapılan modeller}

\section{$1 \mathrm{~mm}-1 \mathrm{~mm}$ model ball ataçman}

İki implant arasında alveolar kret bölgesinin krete yakın alanını içine alan iki implant arasını kaplayan geniş bir yayılım gösteren orta derecede $(1,08)$ stres gözlendi. Her iki implantın apikalinde (sağ implant apikal 1,82, sol implant apikal 1,63) biraz yoğunluk farkı olsa da orta derecede stres gözlendi.

\section{$1 \mathrm{~mm}-2 \mathrm{~mm}$ model ball ataçman}

$2 \mathrm{~mm}$ dişeti yüksekliğine sahip abutment bulunan sol taraftaki implantın distal koronal bölgesinde geniş alana dağılan orta derecede $(1,39)$ stres gözlenirken apikal bölgesinde de orta derecede $(1,63)$ stres bantları gözlendi. İki implant arasında alveol kret tepesinden uzaklaşan implantlarla bağlantılı geniş alana yayılan orta derecede $(1,08)$ stres gözlenirken sağ taraftaki implantın apikal bölgesinde orta derecede $(2,00)$ stres gözlendi.

\section{1mm-4 mm model ball ataçman}

$4 \mathrm{~mm}$ dişeti yüksekliğine sahip abutment bulunan implantın apikal bölgesinde orta derecede $(2,35)$ stres gözlendi. İki implant arasında yine orta derecede $(1,08)$ stres bulunurken stres dağılımı kret tepesinden uzak ve dar alanda görüldü. Sağ taraftaki implantın ise (1mm dişeti yüksekliğine sahip abutment bulunan) apikal bölgesinde orta derecede $(2,50)$ stres bandı gözlendi. Koronal bölgede herhangi bir stres bandı oluşmadı. 


\section{$1 \mathrm{~mm}-1 \mathrm{~mm}$ model locator ataçman}

Sol taraftaki implantın apikal bölgesinde orta derecede $(1,39)$ stres gözlemlendi. Sağ taraftaki implantın apikalinde ise orta derecede $(1,63)$ stres gözlendi. Mezial $(1,08)$ ve distal $(1,22)$ koronal bölgelerinde karşıt implantın simetriği orta derecede stresler gözlendi. İki implant arasında alveolar kret bölgesinde herhangi bir strese rastlanmadı.

\section{$1 \mathbf{m m}$ - 2mm model locator ataçman}

$2 \mathrm{~mm}$ dişeti yüksekliğine sahip abutment bulunan sol taraftaki implantın apikal bölgesinde orta derecede $(1,63)$ stres gözlendi. İki implant arasında ise geniş alana dağılım gösteren alveolar kret bölgesine yakın seyreden düşük derecede $(0,90)$ stres gözlendi. Karşı taraftaki implantın apikal bölgesinde orta derecede $(2,35)$ stres gözlendi.

\section{$1 \mathrm{~mm}-4$ mm model locator ataçman}

Sol taraftaki implantın apikal bölgesinde orta derecede $(1,63)$ stres gözlendi. İki implant arasında orta dereceli $(1,00)$ nispeten küçük alana dağılım gösteren stres gözlendi. Karşı taraftaki implantın (1mm dişeti yüksekliğine sahip abutment bulunan) apikal bölgesinde orta derecede $(1,39)$ stres gözlendi.

\section{TARTIŞMA}

$\mathrm{Bu}$ çalışmada $1 \mathrm{~mm}-1 \mathrm{~mm}$ mukoza kalınlığına sahip modellerde elde edilen stres yoğunluğu değerleri, $1 \mathrm{~mm}-2 \mathrm{~mm}$ ve $1 \mathrm{~mm}-4 \mathrm{~mm}$ mukoza kalınlıklarına sahip olan modellerden elde edilen değerlerden daha az çıkmıştır. Bu farkın ball ataçman tipi modellerde locator tipinden daha fazla olduğu belirlenmiştir. Bu sebepten dolayı çalışmanın hipotezi reddedilmiştir.

Fotoelastik stres analizinin diş hekimliğinde; doğal dişlerin etrafında, sabit parsiyel protezlere ve hareketli parsiyel protezlere destek olacak dişlerin etrafında ve osseointegre implantların çevresindeki alanlarda oluşabilecek streslerin belirlenmesinde yaygın bir kullanımı vardır. ${ }^{22,26-33}$ Birçok çalışmada fotoelastik model içindeki stres şekillerinin doğal yapılarınkine çok yakın çıktığı rapor edilmiştir. ${ }^{29-33}$ Çünkü modelde stres dağılımı direkt olarak gözlenebilir ve oluşan stresin şekli ve oluştuğu alanla doğal yapıların arasında benzerlik vardır. ${ }^{34}$ Periodonsiyumu ve implantların durumunu tek bir rezinden oluşarak temsil etmesine rağmen, kortikal ve spongiyoz kemik arasında fark yok sayılmıştır, stres konsantrasyonun ve şiddetinin büyüklüğü değişebilir fakat stresin konsantrasyonun oluştuğu bölgeler önemli ölçüde değişme- yecektir. ${ }^{26,28}$ Böylece analiz sonuçları implantlar ve çevredeki kemik doku hakkında doğru tahminler yapılmasına yardım eder. ${ }^{35}$

Daha önceki çalışmalarda olduğu gibi çalışmamızda rezinin kalıp içerisinde sertleştirilmesi yöntemi uygulandı. $^{22,28}$ Çalışmamızda kullanılan implantlar önce akrilik modellerde hazırlanan yuvalara yerleştirildi daha sonra silikon ölçünün içerisine yerleştirilip foto- elastik rezin negatif kalıba döküldü. Bu yöntemle fotoelastik modellerde yuva hazırlanma esnasında oluşabilecek streslerin önüne geçilmesi hedeflendi. Bu işlem başarılı osseointegrasyonun taklidi için önemlidir. Çalışmamızda, yapılan fotoelastik stres analizinde kemik ve implantın linear özelliğe sahip olması gerekliliği nedeniyle implantın, kortikal ve spongiyoz kemikle $\% 100$ osseointegre ve temas halinde olduğu kabul edildi.

Önceki fotoelastik çalışmaların çoğunda 22,26-33 anterior bölgede bulunan implantların çevresindeki mukoza elimine edilmiş, deney modellerinde sadece posterior bölgede protezin altına yapay mukoza materyali yerleştirilmiştir. Çalışmaların sonuçlarında da bu durum in vivo koşulları tam taklit etmediğinden dolayı eksiklik olarak belirtilmiştir. Bu çalışmada ise anteriordaki implantlar çevresinde yapay mukozayı taklit eden materyalin (Gingifast; Zhermack SpA, Badia Polesine, İtalya) kullanılması ile ağız ortamına daha yakın koşullar sağlanmaya çalışıldı.

Overdenture protezlerde yapılan planlama kadar yerleştirilecek olan implantların sayı ve lokalizasyonları, implant ve destekleyen kemikteki yüklemeyi etkileyecektir. McGill konsensusuna göre kemik desteği yeterliyse iki implant destekli overdenture ilk tedavi seçeneği olarak düşünülmelidir. ${ }^{2} \mathrm{Bu}$ çalışmada da birbirinden bağımsız iki implant kullanılarak yapılan overdenture protezlerde destek dokulara iletilen stresin şiddeti belirlenmeye çalışılmıştır.

Literatür taraması sonucunda overdenture protezlerde implant ile bağlantıyı sağlamak için genellikle bar-klip 22,25,33, ball 22,36, ball/O'ring 25,29, ERA 27,35,37, locator $^{22,27}$ ve magnet ${ }^{36}$ gibi farklı hassas tutucular kullanıldığı belirlendi. Çalışmamızda ataçman tipi olarak literatürde iki bağımsız implant destekli overdenture yapımında sıklıkla kullanılan ball ataçmanla daha az kullanılmış ancak kullanımı gittikçe artan locator hassas tutucu karşılaştırıldı.

Machado ve ark'larının ${ }^{28}$ üç faklı ataçman sisteminin implant destekli mandibular overdenture'larda implantlara iletilen streslere etkisini araştırdıkları çalış-

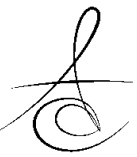


malarında bar sisteminde implantlarda $100 \mathrm{~N}^{\prime}$ luk kuvvet altında oluşan stresler orta seviyede iken O'ring ataçman sisteminde implant çevresinde düşük seviyede stres bulmuşlardır. da Silva ve ark'larının ${ }^{38}$, alt çene fotoelastik modellere 67 N'luk kuvvet uygulayarak farklı tutucu tiplerinin alveolar kemiğe ve implantlara ilettiği stresi inceledikleri çalışmada O'ring ataçman sisteminin implantlara orta seviyede stres ilettiğini bulmuşlardır.

Fanuscu ve Caputo $^{37}$ iki faklı ataçman sisteminin (ball, bar-ERA) üst çene overdenturelarda implantlara gelen kuvvet iletimini inceledikleri çalışmada modellere ikinci premolar bölgesinden 144 N'luk yük uygulamışlardır. Ball ataçman sisteminin yükleme yapılan implantta yüksek seviyede stres iletimine neden olduğunu belirtmişlerdir. Çalışmamızda tüm deney modellerinde hem ball hem de locator sistem implant-kemik ara yüzeyine orta derecede stres ilettiği gözlendi. da Silva ve ark'larının rezeke çeneye uyguladıkları 67 N'luk kuvvet tam çenede 135N'a karşılık geleceğinden çalışmada çıkan orta derecedeki stres çaışmamızla uyumlu iken diğer araştırmacılar ile uyumlu değildir. Araştırmalarda çıkan stres büyüklüğündeki farklııılar çalışmalarda uygulanan kuvvetin büyüklüğündeki ve uygulama sahasının anterior dişlere yakınlığındaki farklılıklara bağlı olduğu düşünülmektedir. Yükün uygulama sahasının anteriordan posteriora kaydırılması dişsiz sahada stresin artmasına, implantlarda ise stresin azalmasına neden olduğu

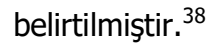

Hojo ve ark'ları ${ }^{39}$ iki implant destekli mandibular overdenture protezlerde magnet, locator ve ERA rezilient ataçman tiplerinin implantlara çift taraflı yük iletimlerini fotoelastik kuvvet analiz yöntemiyle karşılaştırdıkları çalışmalarında en yüksek stres değerlerini sırasıyla magnet tutucular, ERA, locator olarak buldukIarını rapor etmiştir. Çalışmamızda elde ettiğimiz sonuçlar önceki çalışmanın sonuçlarına benzerdir. Farklı mukoza kalınlığına sahip modellerde locator dizaynı ball ataçman tipine göre implantlara ve alveolar krete daha dengeli ve az stres iletttiği gözlendi. Bunun sebebi ball ataçman ile tutuculuğun sağlandığı protezlerde tutucu sisteminin dizaynı gereği erkek ve dişi parçaları arasında boşluk yoktur ve uygu-lanan kuvvet implantlara direkt olarak iletilir. Locator ataçmanlar gibi reziliens tipte ataçmanlar okluzal yükler altında terminal konuma geldiği zaman erkek ve dişi parça arasındaki boşluğun stres azaltıcı etkisi ile implantlar üzerine doğrudan iletilen kuvvetler azaltılmış olur. ${ }^{19}$ Ayrıca locator tutucularda mukoza desteği daha fazla olduğundan kuvvetin bir kısmı mukoza aracılığıyla yükleme noktasındaki alveolar krete iletilebilir.

İmplantlarda gözlenen en yüksek stres konsantrasyonu, implant (20-30 $\mu \mathrm{m})$ ve mukoza (yaklaşık $500 \mu \mathrm{m}$ ) arasındaki reziliens farkı sebebiyle gerçekleşir ${ }^{36,40}$. Bu yüzden, daha reziliens bir mukoza implantlar üzerinde stres değerlerini artırır. ${ }^{1,36}$ Reziliens bir ma teryale kuvvet uygulandığında madde, kuvvetin bir kısmını üzerine alır, enerjiyi abzorbe ederek şekil değiştirir. Başlangıçta kuvvet uygulanmasıyla deformasyon artmaya başlarken deformasyonun belli bir seviyeye ulaşması ile aynı miktarda kuvvet uygulanması, daha önce ölçülenle aynı miktarda deformasyon oluşturmaz. Madde tamamen sıkıştıktan sonra katı cisim gibi davranmaya başlar ve kuvveti katı cisim prensiplerine göre iletir. $\mathrm{Bu}$ nedenle reziliens bir materyal ile kaplı olan modele kuvvet uygulanması ile oluşan deformasyonu gösteren grafiğin, parabolik bir seyir göstermesi beklenir. Reziliens materyalin sıkışması tamamlandığında, uygulanan kuvvet ve oluşan deformasyon, birbiri ile doğru orantılı olur. ${ }^{41,42} \mathrm{Bu}$ bilgiler ışığında $1 \mathrm{~mm}-1 \mathrm{~mm}$ mukoza kalınlığında ve $1 \mathrm{~mm}-4 \mathrm{~mm}$ mukoza kalınlığındaki modellerde mukoza materyali kuvvet altında sert doku gibi davranırken $1 \mathrm{~mm}-2 \mathrm{~mm}$ mukoza kalınlığındaki modellerde yumuşak mukoza gibi davrandığı düşünülmektedir. Locator tutucu tipinde $1 \mathrm{~mm}-2 \mathrm{~mm}$ modellerde diğer modellere göre daha yüksek stres gözlenirken $1 \mathrm{~mm}-4 \mathrm{~mm}$ modellerde stres yoğunluğunun azalmasının yukarıda açıklanan yumuşak dokuların belli bir kalınlıktan sonra sıkışarak katı materyal gibi davranma özelliğine bağlanabilir. Ball ataçman tutucu tipinde ise $1 \mathrm{~mm}$ $4 \mathrm{~mm}$ modeldeki stres yoğunluğu azalmayarak orta seviyedede de olsa biraz artış gösterdi. Bunun sebebinin ise ball ataçmanın locator sistemi kadar mukoza desteğinden yararlanamayıp stres iletimini hem implantlara hem de implantlar arası krete iletmesi olduğu düşünülmektedir.

Assunçao ve ark'larının ${ }^{1}$ sonlu eleman kuvvet analiz yöntemi ile yaptıkları çalışmada üç farklı mukoza kalınlıklarına (1mm-3mm-5mm) sahip implant destekli overdenture protezler ile mukoza destekli tam protezlerin stres iletimini araştırmışlardır. Gruplar arasında maksimum stres dağılımları göz önüne alındığında, overdenture grup tam protez gruptan daha yüksek stres değerleri gösterdiğini rapor etmişlerdir. İmplant 
destekli overdenture protezlerde mukoza reziliensi ve kalınlığı arttığında maksimum stres değerlerinin arttığını bulmuşlardır. Çalışmamız Assunçao ve ark'larının çalışmasıyla kısmen uyumludur. Çalışmamızda ball ataçman tutucu tipinde önceki çalışmaya uyumlu olarak mukoza kalınlığı arttıkça stres artışı gözlenirken locator ataçmanda $1 \mathrm{~mm}-2 \mathrm{~mm}$ modelin önceki çalışmanın tersine mukoza artışının 4mm'ye yükseldiği modellerde oluşan stresin düştüğü gözlenmiştir. Önceki çalışmada mukoza yüksekliklerinin çenenin her iki bölgesinde de simetrik olmasından bizim modellerimizde ise $1 \mathrm{~mm}-1 \mathrm{~mm}$ modeller haricinde çenenin iki bölgedesindeki mukoza kalınlıklarının farklı olmasından ve kullanılan analiz metodundaki farklılığa bağlı kemiği homojen ve izotropik varsayarak ${ }^{8}$ mukozanın katı materyal gibi etkileşime girebileceğinin gözardı edilmesinden kaynaklandığı düşünülmektedir. Locator sisteminin ball ataçmana göre mukoza desteğinin fazla olmasından dolayı kemik-mukozadaki etkileşimden çok daha fazla etkilenmesine bağı olarak çalışmamızdaki farkın çıktığını düşünmekteyiz.

Meijer ve ark'larının ${ }^{43}$ iki boyutlu sonlu eleman kuvvet analizi kullanarak implant destekli overdenturelarda stres dağılımını değerlendirdikleri çalışmalarında; stresin splintlenmeyen implantların mezial ve distal tarafında yoğunlaştığını bulmuşlardır. Bu çalışmada da Meijer ve ark'nın çalışmalarına benzer şekilde implantların mezial ve distal taraflarında stres yoğunluğu gözlemlenmiştir. Bunun nedeni bağımsız destekler üzerine yapılan bir protezde alt çene çiğneme kuvvetlerinin implantları birbirlerine doğru yaklaşmaya zorlamasından kaynaklanmaktadır. ${ }^{44}$

İmplantlar veya çevre sert dokularda yıkıma yol açabilecek kuvvetlerin büyüklüğü bilinmediğinden rehabilitasyonun uzun ömürlü olması için kuvvetlerin olabildiğince azaltılmaya çalışılmasında fayda vardır. ${ }^{35}$ İn vivo koşullarda yükleme yönü ve büyüklüğü in vitro koşuldan çok farklı olmaktadır. ${ }^{22}$ Çalışmamızda incelenen okluzal yükler sadece vertikal yönde olmasına rağmen ağızda horizontal yönde kuvvetler de oluşmaktadır. Ayrıca implantlar etrafındaki kemik yapısı apikal, orta ve kök bölgesinde farklı olmasına rağmen deneysel modellerde aynı yapıda kabul edilmektedir. Bu nedenle biyomekaniğin daha iyi anlaşılabilmesi için implantların çevresindeki kemiğin mekanik özellikleri, overdenture'ı destekleyen mukozanın özellikleri ve ağızda oluşan tüm kuvvetler gibi, laboratuvar koşullarında taklit edilemeyen değişkenlerin etkilerini ince- lemek amacıyla, in vivo çalışmaların planlanmasında fayda vardır.

\section{SONUÇ}

Çalışmamızın limitasyonları dahilinde şu sonuçlar elde edilmiştir;

1) Tüm modellerde mukoza kalınlığı ve ataçman tipi farketmeksizin her iki implantta orta derecede stres iletimi gözlenmiştir.

2) Mümkün olduğunca implantlar eşit kemik yüksekliğinde yerleştirilip eşit mukoza kalınlığı oluşturulmasına dikkat edilmelidir.

3) Cerrahi işlem sonrasında farklı kemik yüksekliği ve farklı mukoza kalınlıklarına sahip implantlar üzerine overdenture protezler yapılmak zorunda kalındığında ball ataçman yerine locator tutucu tipinin, implantlara iletilecek stresleri nispeten dengeleyerek implantların prognozunu olumlu etkileyecektir.

ö. Yusuf Özyılmaz: ORCID ID: 0000-0003-4802-1604 Filiz Aykent: ORCID ID: 0000-0001-7346-3717

\section{KAYNAKLAR}

1. Assunção WG, Barão VA, Tabata LF, de Sousa EA, Gomes EA, Delben JA. Comparison Between Complete Denture and Implant-Retained Overdenture: Effect of Different Mucosa Thickness and Resiliency on Stress Distribution. Gerodontology 2009;26:273-81.

2. Feine JS, Carlsson GE, Awad MA, Chehade A, Duncan WJ, Gizani S ve ark. The McGill Consensus Statement on Overdentures. Mandibular TwoImplant Overdentures as First Choice Standard of Care for Edentulous Patients. Gerodontology 2002;19:3-4.

3. Bal BT, Kurt M, Kahraman S. Rehabilitation of An Edentulous Patient with Severely Resorbed Ridges Using Bar Retained Implant Overdentures: A Case Report. J Dent Fac Ataturk Uni 2016; 26:482-86.

4. Hong HR, Pae A, Kim Y, Paek J, Kim HS, Kwon KR. Effect of Implant Position, Angulation, and Attachment Height on Peri-Implant Bone Stress Associated with Mandibular Two-Implant Overdentures: A Finite Element Analysis. Int J Oral Maxillofac Implants 2012; 27:69-76.

5. Batenburg RH, Meijer HJ, Raghoebar GM, Vissink A. Treatment Concept for Mandibular Overdentures Supported By Endosseous Implants: A Literature

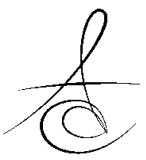


Review. Int J Oral Maxillofac Implants 1998;13:53945.

6. Weibrich G, Buch RS, Wegener J, Wagner W. FiveYear Prospective Follow-Up Report of the Astra Tech Standard Dental Implant In Clinical Treatment. Int J Oral Maxillofac Implants 2001;16:557-62.

7. Esposito M, Grusovin MG, Coulthard P, Thomsen P, Worthington HV. A 5-Year Follow-Up Comparative Analysis of the Efficacy of Various Osseointegrated Dental Implant Systems: A Systematic Review of Randomized Controlled Clinical Trials. Int J Oral Maxillofac Implants 2005;20:557-68.

8. Assunção WG, Tabata LF, Barão VA, Rocha EP. Comparison of Stress Distribution Between Complete Denture and Implant-Retained Overdenture- 2D FEA. J Oral Rehabil 2008;35:766-74.

9. Stellingsma K, Slagter AP, Stegenga $B$, Raghoebar GM, Meijer HJ. Masticatory Function In Patients with An Extremely Resorbed Mandible Restored with Mandibular Implant-Retained Overdentures: Comparison of Three Types of Treatment Protocols. J Oral Rehabil. 2005;32:403-10.

10. Schmitt A, Zarb GA. The Notion of ImplantSupported Overdentures. J Prosthet Dent 1998;79:60-5.

11. Krennmair G, Seemann R, Fazekas A, Ewers R, Piehslinger E. Patient Preference and Satisfaction with Implant-Supported Mandibular Overdentures Retained with Ball or Locator Attachments: A Crossover Clinical Trial. Int J Oral Maxillofac Implants 2012;27:1560-8.

12. Weinländer $M$, Piehslinger $E$, Krennmair G. Removable Implant-Prosthodontic Rehabilitation of the Edentulous Mandible: Five-Year Results of Different Prosthetic Anchorage Concepts. Int J Oral Maxillofac Implants 2010;25:589-97.

13. Cune $M$, van Kampen $F$, van der Bilt A, Bosman F. Patient Satisfaction and Preference with Magnet, Bar-clip, and Ball-Socket Retained Mandibular Implant Overdentures: A Cross-Over Clinical Trial. Int J Prosthodont 2005;18:99-105.

14. Ellis JS, Burawi G, Walls A, Thomason JM. Patient Satisfaction with Two Designs of Implant Supported Removable Overdentures; Ball Attachment and Magnets. Clin Oral Implants Res 2009;20:1293-8.

15. Kleis WK, Kämmerer PW, Hartmann S, Al-Nawas B, Wagner W. A Comparison of Three Different Attachment Systems for Mandibular Two-Implant
Overdentures: One-Year Report. Clin Implant Dent Relat Res 2010;12:209-18.

16. Bilhan H, Geckili O, Mumcu E, Bilmenoglu C. Maintenance Requirements Associated with Mandibular Implant Overdentures: Clinical Results After First Year of Service. J Oral Implantol 2011;37:697-704

17. Bilhan H, Geckili O, Sulun T, Bilgin T. A Quality of Life Comparison Between Self-Aligning and Ball Attachment Systems for 2-Implant-Retained Mandibular Overdentures. J Oral Implantol 2011;37:167-73

18. Ozan O, Ramoglu S. Effect of Implant Height Differences on Different Attachment Types and PeriImplant Bone in Mandibular Two-Implant Overdentures: 3D Finite Element Study. J Oral Implantol 2015;41:50-9.

19. Misch CE. Dental Implant Prosthetics. 2th Ed. St. Louis; Elsevier Mosby: 2005. p.51-6

20. Vogel RC. Implant Overdentures: A New Standard of Care for Edentulous Patients Current Concepts and Techniques. Compend Contin Educ Dent 2008;29:270-6.

21. Osman RB, Elkhadem AH, Ma S, Swain MV. Finite Element Analysis of A Novel Implant Distribution to Support Maxillary Overdentures. Int J Oral Maxillofac Implants 2013;28:1-10.

22. Celik G, Uludag B. Photoelastic Stress Analysis of Various Retention Mechanisms on 3-ImplantRetained Mandibular Overdentures. J Prosthet Dent 2007;97:229-35.

23. Takeshita S, Kanazawa M, Minakuchi S. Stress Analysis of Mandibular Two-Implant Overdenture with Different Attachment Systems. Dent Mater J 2011;30:928-34.

24. Van Steenberghe D, Lekholm U, Bolender C, Folmer $T$, Henry $\mathrm{P}$, Herrmann I ve ark. Applicability of Osseointegrated Oral Implants in the Rehabilitation of Partial Edentulism: A Prospective Multicenter Study on 558 Fixtures. Int J Oral Maxillofac Implants 1990;5:272-81.

25. Chun HJ, Cheong SY, Han JH, Heo SJ, Chung JP, Rhyu IC ve ark. Evaluation of Design Parameters of Osseointegrated Dental Implants Using Finite Element Analysis. J Oral Rehabil 2002;29:565-74.

26. Sadowsky SJ, Caputo AA. Stress Transfer of Four Mandibular Implant Overdenture Cantilever Designs. J Prosthet Dent 2004;92:328-36. 
27. Ochiai KT, Williams BH, Hojo S, Nishimura R, Caputo AA. Photoelastic Analysis of the Effect of Palatal Support on Various Implant-Supported Overdenture Designs. J Prosthet Dent 2004;91:421-7.

28. Machado AC, Cardoso L, Brandt WC, Henriques GE, de Arruda Nobilo MA. Photoelastic Analysis of the Distribution of Stress in Different Systems of Overdentures on Osseous-Integrated Implants. J Craniofac Surg 2011;22:2332-6.

29. Mazaro JV, Filho HG, Vedovatto E, Pellizzer EP, Rezende MC, Zavanelli AC. Evaluation of Stress Patterns Produced By Implant-Retained Overdentures and Implant-Retained Fixed Partial Denture. J Craniofac Surg 2011;22:2153-7.

30. Asvanund P, Morgano SM. Photoelastic Stress Analysis of External Versus Internal ImplantAbutment Connections. J Prosthet Dent 2011;106:266-71.

31. Teixeira FM, de Assis Claro CA, Neves AC, de Mello Rode S, da Silva Concílio LR. Influence of Loading and Use of Occlusal Splint in Implant-Supported Fixed Prostheses. J Craniofac Surg 2012;23:477-80.

32. Ueda C, Markarian RA, Sendyk CL, Lagana DC. Photoelastic Analysis of Stress Distribution on Parallel and Angled Implants After Installation of Fixed Prostheses. Braz Oral Res 2004;18:45-52.

33. Sadowsky SJ, Caputo AA. Effect of Anchorage Systems and Extension Base Contact on Load Transfer with Mandibular Implant-Retained Overdentures. J Prosthet Dent 2000;84:327-34.

34. Markarian RA, Ueda C, Sendyk CL, Lagana DC, Souza RM. Stress Distribution After Installation of Fixed Frameworks with Marginal Gaps Over Angled and Parallel Implants: A Photoelastic Analysis. J Prosthodont 2007; 16:117-22.

35. Porter JA Jr, Petropoulos VC, Brunski JB. Comparison of Load Distribution for Implant Overdenture Attachments. Int J Oral Maxillofac Implants 2002;17:651-62.

36. Ichikawa T, Horiuchi M, Wigianto R, Matsumoto N. In vitro Study of Mandibular Implant-Retained Overdentures: The Influence of Stud Attachments on Load Transfer to the Implant and Soft Tissue. Int J Prosthodont 1996;9:394-9.

37. Fanuscu MI, Caputo AA. Influence of Attachment Systems on Load Transfer of An Implant-Assisted Maxillary Overdenture. J Prosthodont 2004;13:21420.
38. da Silva DP, Cazal C, de Almeida FC, Dias RB, Ballester RY. Photoelastic Stress Analysis Surrounding Implant-Supported Prosthesis and Alveolar Ridge on Mandibular Overdentures. Int J Dent 2010;1:1-5

39. Hojo S, Ochiai K, Sadowsky S, Toyoda M, Caputo AA. Mandibular Implant Overdentures Load Transfer with Magnetic and Resilient Attachments. (13.03.2004).

URL:http://iadr.confex.com/iadr/2004Hawaii/techpro gram/abstract_42356.htm Erişim tarihi: 08/01/2017.

40. Barao VA, Assunçao WG, Tabata LF, de Sousa EA, Rocha EP. Effect of Different Mucosa Thickness and Resiliency on Stress Distribution of Implant-Retained Overdentures-2D FEA. Comput Methods Programs Biomed 2008;92:213-23.

41. Shigeto N, Hamada T, Iwanaga $H$, Murata $H$. Pressure Distribution Using Tissue Conditioners on Simplified Edentulous Ridge Models. Part 1: The influence of the Height of the Residual Ridge. Int J Prosthodont 1995;8:490-5.

42. Bidez MW, Misch CE. Force Transfer in Implant Dentistry: Basic Concepts and Principles. J Oral Implantol 1992;18:264-74.

43. Meijer HJ, Kuiper JH, Starmans FJ, Bosman F. Stress Distribution Around Dental Implants: Influence of Superstructure, Length of Implants, and Height of Mandible. J Prosthet Dent 1992;68:96-102.

44. Menicucci G, Lorenzetti M, Pera P, Preti G. Mandibular Implant-Retained Overdenture: Finite Element Analysis of Two Anchorage Systems. Int J Oral Maxillofac Implants 1998;13:369-76.

\author{
Yazışma Adresi \\ Dr Öğretim Üyesi Özgün Yusuf Özyılmaz \\ İstanbul Bezmialem Vakıf Üniversitesi \\ Diş Hekimliği Fakültesi \\ Protez Anabilim Dall, İstanbul, Türkiye \\ Tel: 02124531700 \\ Fax: 02124531869 \\ e-mail: oozyilmaz@bezmialem.edu.tr
}

